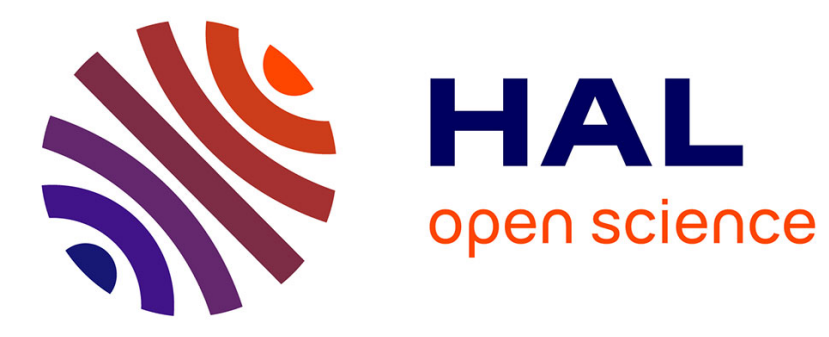

\title{
Motor Current Signal Analysis Based on a Matched Subspace Detector
}

Elhoussin Elbouchikhi, Vincent V. Choqueuse, François Auger, Mohamed

Benbouzid

\section{- To cite this version:}

Elhoussin Elbouchikhi, Vincent V. Choqueuse, François Auger, Mohamed Benbouzid. Motor Current Signal Analysis Based on a Matched Subspace Detector. IEEE Transactions on Instrumentation and Measurement, 2017, 66 (12), pp.3260 - 3270. 10.1109/TIM.2017.2749858 . hal-01651982

\section{HAL Id: hal-01651982 \\ https://hal.univ-brest.fr/hal-01651982}

Submitted on 29 Nov 2017

HAL is a multi-disciplinary open access archive for the deposit and dissemination of scientific research documents, whether they are published or not. The documents may come from teaching and research institutions in France or abroad, or from public or private research centers.
L'archive ouverte pluridisciplinaire HAL, est destinée au dépôt et à la diffusion de documents scientifiques de niveau recherche, publiés ou non, émanant des établissements d'enseignement et de recherche français ou étrangers, des laboratoires publics ou privés. 


\title{
Motor Current Signal Analysis based on a Matched Subspace Detector
}

\author{
Elhoussin Elbouchikhi, Member, IEEE, Vincent Choqueuse, Member, IEEE, \\ François Auger, Senior Member, IEEE, and mohamed Benbouzid, Fellow Member, IEEE
}

\begin{abstract}
Motor current signature analysis (MCSA) is a well-proven technique for electrical and mechanical faults detection in induction motors. The appearance of stator current components or increase of magnitude of some components at characteristic frequencies indicates a motor fault condition. In this paper, we propose a new MCSA fault detector based on a matched subspace technique. The proposed detector consists of three steps. First, the influence of the fundamental supply frequency is removed from the current signal using an interference cancellation technique based on oblique projection. Then, the fault-related frequency is estimated from the interference-free signal using the maximum likelihood (ML) principle. Finally, the fault detection is performed using a generalized likelihood ratio test. Simulation and experimental results illustrate the effectiveness of the proposed approach for eccentricity fault, bearing faults and broken rotor bars detection.
\end{abstract}

Index Terms-Induction motor, Diagnosis, Fault detection, Eccentricity fault, Broken rotor bars, Bearing faults, Subspace Matched Detector, Oblique projection, MCSA.

\section{INTRODUCTION}

I NDUCTION motors are one of the most commonly used motors in industrial applications. Despite their efficiency and robustness, induction motors can breakdown due to several faults such as bearings, stator, rotor, or eccentricity faults [1]. These unexpected breakdowns are very expensive in terms of time and money. In this context, reducing operation and maintenance costs is of main concern in such industrial applications. Consequently, preventive maintenance is preferred over the corrective maintenance. In fact, the preventive maintenance is intended to reduce the probability of failure, minimize downtime and maximize productivity. It includes the scheduled and condition-based maintenance [2]. Unlike the scheduled maintenance, the condition-based one monitors the current state of the induction machine and schedules the maintenance actions at the optimum time. Several techniques have been proposed for induction machines condition monitoring such as vibration, torque, temperature, current/power monitoring or

Elhoussin Elbouchikhi is with the ISEN Brest, FRE CNRS 3744 IRDL - Institut de Recherche Dupuy de Lôme, 20, Rue Cuirassé Bretagne, 29200 Brest, France (email: elbouchikhi@isen-bretagne.fr. Vincent Choqueuse and Mohamed Benbouzid are with the University of Brest, FRE CNRS 3744 IRDL - Institut de Recherche Dupuy de Lôme, Rue de Kergoat, CS 93837, 29238 Brest Cedex 03, France (email: Youness.Trachi@univ-brest.fr, Vincent.Choqueuse@univ-brest.fr, Mohamed.Benbouzid@univ-brest.fr). Mohamed Benbouzid is also with the Shanghai Maritime University, 201306 Shanghai, China.

François Auger is the University of Nantes/IUT of Saint-Nazaire, EA 4642 IREENA, 58 Rue Michel Ange, 44606 Saint-Nazaire, France. oil/debris analysis [3]. Among them, motor current signature analysis (MCSA) is one of the most promising solutions since this technique is non-invasive and avoids the use of extra sensors [4].

In this context, MCSA has been widely investigated for induction machine condition monitoring as the stator currents constitute a reliable information source. In fact, an induction machine is a highly symmetrical electromagnetic system. Consequently, any fault may cause some degree of asymmetry. This asymmetry induces a disturbance of the rotating electromagnetic field in the air gap, which straightforwardly affects the stator currents. Several works have presented numerical machine models under faults based on finite element methods or analytical methods based on modified winding function approach (MWFA). Moreover, the consequences of mechanical and electrical faults have been also theoretically investigated using the magnetomotive force (MMF) and permeance wave approach for airgap magnetic flux density computation [5]. These contributions allow to understand the effect of some phenomena, but do not provide the exact sub-harmonics amplitude introduced by the fault. The faults effects on the stator currents can be grouped into three major contributions, which are: the impact on the stator current power spectral density (PSD) [6], the amplitude and/or phase modulation of the stator currents [7], [8], and the impact over the negative-sequence component [9].

Induction machine faults diagnosis based on MCSA consists of faults characteristics extraction based on signal processing techniques followed by a fault detection procedure. Several approaches have been presented for stator currents processing and reliable fault detection [5], [6]. Nevertheless, the detection step is often performed manually, based on visual inspection of the fault signature on the stator currents. To automatically detect a fault, several authors have proposed algorithms based on threshold detectors [10], [11]. However, the implementation of these techniques requires the user to set a threshold manually, based on the knowledge of the induction machine to be supervised. To avoid the need of manual setting, several pattern recognition techniques have been investigated for decision making. These techniques include Artificial Neural Networks [12], Support Vector Machines [13], Fuzzy Logic [14], and combined techniques. Nevertheless, these techniques are black-box methods whose parameters are difficult to tune in practice. Moreover, the detection performance critically depends of the learning database. In fact, the training phase is critical for optimal operation and may be misleading or pro- 
duce results limited to a particular set of faults. Moreover, the learning database must be sufficiently large depending on the studied faults and the induction machine operating conditions. However, a large learning database may lead to over-fitting problems thus limiting the generalisation capabilities of the detector [15].

Induction motor stator currents contain several spectral components due to the supply voltage, rotor slotting and iron saturation [16]. In case of faults, additional frequency components also appear in the current spectrum. To reveal these additional components, several spectral analysis techniques can be used such as the FFT [17], MUSIC [18], [19], and ESPRIT algorithms [10], [20]. However, these general spectral estimators do not exploit the particular spectrum structure induced by the fault. Moreover, these approaches only focus on the current spectral analysis and do not provide any algorithm for automatic fault detection. In [10], [21], the authors have proposed a Maximum Likelihood (ML) parametric estimator for current spectral analysis, and a simple ad-hoc fault criterion. In [11], the same fault criterion is used in conjunction with an interference cancellation technique for the removal of the supply component at $50 \mathrm{~Hz}$. However, in these two studies, no strategy has been provided to automatically detect a fault from the estimated spectral components.

As compared to the techniques in [11], [21], this paper directly focuses on the MCSA fault detection problem. Specifically, we propose a new matched subspace detector that treats the supply frequency components as an interference signal. To remove the supply frequency component, the authors in [18] have proposed a Kalman-based technique. However, this technique is suboptimal from a statistical sense when the fundamental frequency is quasi-stationary (i.e. when the frequency and the amplitude vary smoothly with time). In this study, the interference signal is removed from the raw data using an oblique projection. Then, the fault detection problem is formulated as a binary hypothesis test and solved using the Generalized Likelihood Ratio Test (GLRT). In [22], a general GLRT-based approach has been investigated for induction motors fault detection using the raw data. This approach is time consuming and difficult to implement since it requires many matrix inversions. In this paper, the proposed detector allows reducing the computational cost and can be easily implemented using FFT algorithms, which are almost available on DSP-boards. In our case, the GLRT is referred to as a matched subspace detector [23].

The remaining parts of this paper are organized as follows. Section II presents the signal model under faulty conditions. Section III describes the proposed approach for interferencefree signal estimation and the MLE based estimate for fault related frequency. Section IV introduces the proposed fault detection and diagnosis technique, which is performed using a matched subspace detector. Section V deals with the statistical performance evaluation of the proposed approach. Section VI gives experimental results for eccentricity fault, bearing faults, and broken rotor bars. Section VII concludes this paper.

\section{Stator CuRrent Signal Model}

Three induction machine faults are considered in this study: eccentricity fault, bearing faults, and broken rotor bars.

\section{A. Fault Related Frequencies}

1) Eccentricity fault effect over stator currents: When eccentricity occurs in a rotating machine, the effective airgap function varies in a sinusoidal manner with respect to angular position $\theta_{s}$ and time in the stator reference frame [5], [24]. In the literature, two types of eccentricity are commonly considered, which are static and dynamic eccentricities. They can jointly occur leading to the so-called a mixed eccentricity.

Airgap variations have an effect over the airgap permanence function and consequently on the motor inductances. Eccentricity fault effect has been investigated to model the fault impact on stator current [24], [25]. It has been proved, that under eccentricity faults, the stator currents contain the frequencies given by (1).

$$
\omega_{k}=\omega_{s}\left|1 \pm k\left(\frac{1-s}{p}\right)\right|
$$

where $p$ is the pole pairs number. Moreover, eccentricity fault leads to an increase of oscillating torque components at $\omega_{r}=$ $\left(\frac{1-s}{p}\right) \omega_{s}[5]$

2) Bearing faults effects on stator currents: Bearing support the rotor of an induction machine. Consequently, any bearing fault can induce two different effects, which are the introduction of a particular radial rotor movement and some load torque variations [26], [27]. Bearing single-point defects can be monitored by supervising some frequency components around the supply frequency, which are given by

$$
\omega_{k}=\left(\omega_{s}+k \omega_{f}\right),
$$

where $\omega_{f}$ is one of the characteristic vibration angular frequencies given in [21]. Amplitude and frequency of such frequency components depend on shaft rotational speed, fault location, and bearing dimensions.

3) Broken rotor bars effects on stator currents: Broken rotor bar induces a bar resistance increase, which leads to asymmetry of the resistance in rotor equivalent phases. Consequently, broken rotor bars fault induces asymmetry of the rotating electromagnetic field in the air gap. Since stator currents are linked to the airgap electromagnetic field, any broken rotor bar may have an effect over the stator current waveform [28]. This effect is modeled by adding some frequency components on the stator currents PSD [29], [30], which are located at

$$
\omega_{k}=(1+2 k s) \omega_{s},
$$

where is $s$ is the per unit slip, $\omega_{s}$ is the normalized electrical supply fundamental angular frequency and $k \in \mathbb{Z}^{*}$.

\section{B. Stator Current Model Under Faulty Condition}

For the previously discussed three faults , the fault signature can be modeled as additional (normalized) angular frequencies that can be expressed by

$$
\omega_{k}=\omega_{s}+k \omega_{d}
$$


where $\omega_{d}$ is the normalized fault-related angular frequency, and $-k_{1} \leq k \leq k_{2}\left(k \in \mathbb{Z}^{*}\right)$. For eccentricity fault, bearing faults and broken rotor bars, the normalized faultrelated angular frequency are $\omega_{d}=\left(\frac{1-s}{p}\right) \omega_{s}, \omega_{d}=\omega_{f}$ and $\omega_{d}=2 s \omega_{s}$, respectively. In this study, we assume that the supply frequency is equal to its nominal value i.e. $50 \mathrm{~Hz}$ (or $60 \mathrm{~Hz}$ ). In this context, the normalized electrical supply angular frequency is equal to $\omega_{d}=100 \pi / F_{s} \mathrm{rad} / \mathrm{sample}$, where $F_{s}$ corresponds to the sampling rate.

By separating the supply and fault related components, the stator current can be decomposed as

$$
x[n]=s_{1}[n]+s_{2}[n]+b[n],
$$

where:

- $s_{1}[n]=\sum_{\substack{k=-k_{1} \\ k \neq 0}}^{k_{2}} a_{k} \cos \left(\left(\omega_{s}+k \omega_{d}\right) n+\phi_{k}\right)$ corresponds to fault spectral components,

- $s_{2}[n]=a_{0} \cos \left(\omega_{s} n+\phi_{0}\right)$ corresponds to the supply fundamental component,

- $a_{k} \in \mathbb{R}^{+}$and $\phi_{k}$ are the amplitude and initial phase of the $k^{\text {th }}$ component, respectively,

- $b[n]$ corresponds to the noise component. This random component is introduced to model the uncertainty errors that may occur during the measurement, conversion, storage or processing stages. This component is assumed to be a white, Gaussian noise with zero mean and variance $\sigma^{2}$, i.e. $b[n] \sim \mathcal{N}\left(0, \sigma^{2}\right)$. This choice is motivated by the central limit theorem [31], and by the fact that the Gaussian noise assumption leads to largest Cramér-Rao bound [32].

In practice, the signal is observed during a time slice of $N \geq L$ samples, where $L=2\left(k_{1}+k_{2}+1\right)$. By noting $\mathbf{x} \triangleq$ $[x[0], \ldots, x[N-1]]^{T}$ the observed current signal, the signal model in (5) can be written under a matrix form as follows

$$
\mathbf{x}=\mathbf{G}_{1}\left(\omega_{d}\right) \boldsymbol{\theta}_{1}+\mathbf{G}_{2} \boldsymbol{\theta}_{2}+\mathbf{b}
$$

where:

- $\mathbf{G}_{1}\left(\omega_{d}\right) \boldsymbol{\theta}_{1}$ is the additive term that models the influence of the fault-related components. More precisely, $\mathbf{G}_{1}\left(\omega_{d}\right) \in \mathbb{R}^{N \times(L-2)}$ is a matrix given by

$$
\mathbf{G}_{1}\left(\omega_{d}\right) \triangleq\left[\begin{array}{lll}
\mathbf{H}\left(\omega_{s}-k_{1} \omega_{d}\right) & \cdots & \mathbf{H}\left(\omega_{s}+k_{2} \omega_{d}\right)
\end{array}\right]
$$

where

$$
\mathbf{H}(\omega) \triangleq\left[\begin{array}{cc}
1 & 0 \\
\cos (\omega) & -\sin (\omega) \\
\vdots & \vdots \\
\cos (\omega(N-1)) & -\sin (\omega(N-1))
\end{array}\right]
$$

and $\boldsymbol{\theta}_{1} \in \mathbb{R}^{(L-2) \times 1}$ is a column vector defined as

$$
\boldsymbol{\theta}_{1} \triangleq\left[\begin{array}{c}
a_{-k_{1}} \cos \left(\phi_{-k_{1}}\right) \\
a_{-k_{1}} \sin \left(\phi_{-k_{1}}\right) \\
\vdots \\
a_{k_{2}} \cos \left(\phi_{k_{2}}\right) \\
a_{k_{2}} \sin \left(\phi_{k_{2}}\right)
\end{array}\right] \text {. }
$$

It should be emphasized that the matrix $\mathbf{H}\left(\omega_{s}\right)$ and the vector $\boldsymbol{\theta}_{2}=\left[\begin{array}{ll}a_{0} \cos \left(\phi_{0}\right) & a_{0} \sin \left(\phi_{0}\right)\end{array}\right]^{T}$ are excluded from (7) and (9), respectively.

- $\mathbf{G}_{2} \boldsymbol{\theta}_{2}$ is an interference term that models the influence of the supply component. Specifically, $\mathbf{G}_{2} \in \mathbb{R}^{N \times 2}$ is a matrix given by $\mathbf{G}_{2} \triangleq \mathbf{H}\left(\omega_{s}\right)$ and $\boldsymbol{\theta}_{2} \in \mathbb{R}^{2 \times 1}$ is a column vector, which is defined by

$$
\boldsymbol{\theta}_{2} \triangleq\left[\begin{array}{ll}
a_{0} \cos \left(\phi_{0}\right) & a_{0} \sin \left(\phi_{0}\right)
\end{array}\right]^{T} \text {. }
$$

- $\mathbf{b} \triangleq[b[0], \ldots, b[N-1]]^{T}$ contains the additive white noise.

The goal of this paper is to detect a fault, i.e. $\boldsymbol{\theta}_{1} \neq \mathbf{0}$, from the stator current. It should be mentioned that this paper assumes that the values of $k_{1}$ and $k_{2}$ are known. If this condition is not satisfied, these values can be estimated using a model-order selection technique [33].

\section{EStIMATION OF $\omega_{d}$}

Let us denote $\mathbf{G}\left(\omega_{d}\right) \triangleq\left[\mathbf{G}_{1}\left(\omega_{d}\right) \mathbf{G}_{2}\right]$ the $N \times L$ matrix obtained by concatenating the matrices $\mathbf{G}_{1}\left(\omega_{d}\right)$ and $\mathbf{G}_{2}$ and $\boldsymbol{\theta} \triangleq\left[\boldsymbol{\theta}_{1}^{T}, \boldsymbol{\theta}_{2}^{T}\right]^{T}$ the $L \times 1$ vector obtained by concatenating the vectors $\boldsymbol{\theta}_{1}$ and $\boldsymbol{\theta}_{2}$. Under the assumption that $\mathbf{b} \sim \mathcal{N}\left(\mathbf{0}, \sigma^{2} \mathbf{I}\right)$, the ML estimator of $\omega_{d}$ is given by the minimizing argument of the Least Squares function $\left\|\mathbf{x}-\mathbf{G}\left(\omega_{d}\right) \boldsymbol{\theta}\right\|^{2}$ with respect to $\omega_{d}$ and $\boldsymbol{\theta}$ [34]. In this section, we derive the exact and approximate estimators of $\omega_{d}$. Furthermore, we show that these two estimators require the estimation of the interference-free signal.

\section{A. Exact Frequency Estimator}

The minimizing argument of the Least Squares function $\left\|\mathbf{x}-\mathbf{G}\left(\omega_{d}\right) \boldsymbol{\theta}\right\|^{2}$ with respect to $\omega_{d}$ is given by [35]

$$
\widehat{\omega}_{d}=\arg \min _{\omega_{d}} \mathbf{x}^{T} \mathbf{P}_{\mathbf{G}}^{\perp}\left(\omega_{d}\right) \mathbf{x}
$$

where $\mathbf{P}_{\mathbf{G}}^{\perp}\left(\omega_{d}\right) \triangleq \mathbf{I}_{N}-\mathbf{G}\left(\omega_{d}\right)\left(\mathbf{G}^{T}\left(\omega_{d}\right) \mathbf{G}\left(\omega_{d}\right)\right)^{-1} \mathbf{G}^{T}\left(\omega_{d}\right)$ is the orthogonal projector into the kernel of $\mathbf{G}^{T}\left(\omega_{d}\right)$. Due to the particular structure of $\mathbf{G}\left(\omega_{d}\right)$, the estimator of $\omega_{d}$ can also be simplified as [23, Eq 3.6]

$$
\widehat{\omega}_{d}=\arg \min _{\omega_{d}} \mathbf{y}^{T}\left(\mathbf{I}_{N}-\mathbf{E}_{\mathbf{G}_{\mathbf{1}} \mathbf{G}_{\mathbf{2}}}\left(\omega_{d}\right)\right) \mathbf{y}
$$

where $\mathbf{y} \triangleq \mathbf{P}_{\mathbf{G}_{2}}^{\perp} \mathbf{x}$ is the interference-free signal obtained by removing the fundamental angular frequency component, $\mathbf{P}_{\mathbf{G}_{2}}^{\perp}$ is the orthogonal projector into the kernel of $\mathbf{G}_{2}^{T}$, and $\mathbf{E}_{\mathbf{G}_{1} \mathbf{G}_{\mathbf{2}}}\left(\omega_{d}\right)$ corresponds to the oblique projector onto the range of $\mathbf{G}_{\mathbf{1}}\left(\omega_{d}\right)$ along $\mathbf{G}_{\mathbf{2}}$ and is defined as:

$$
\mathbf{E}_{\mathbf{G}_{\mathbf{1}} \mathbf{G}_{\mathbf{2}}}\left(\omega_{d}\right) \triangleq \mathbf{G}_{\mathbf{1}}\left(\omega_{d}\right)\left(\mathbf{G}_{\mathbf{1}}^{\mathbf{T}}\left(\omega_{d}\right) \mathbf{P}_{\mathbf{G}_{\mathbf{2}}}^{\perp} \mathbf{G}_{\mathbf{1}}\left(\omega_{d}\right)\right)^{-1} \mathbf{G}_{\mathbf{1}}^{\mathbf{T}}\left(\omega_{d}\right) \mathbf{P}_{\mathbf{G}_{\mathbf{2}}}^{\perp}
$$

As $\mathbf{G}_{2}$ is a $N \times 2$ matrix, it is interesting to note that the expression of the interference-free signal $\mathbf{y}=\mathbf{P}_{\mathbf{G}_{\mathbf{2}}}^{\perp} \mathbf{x}$ can be derived analytically. Indeed, the interference-free signal expression can be written as

$$
\mathbf{y}=\mathbf{P}_{\mathbf{G}_{\mathbf{2}}}^{\perp} \mathbf{x}=\mathbf{x}-\mathbf{G}_{\mathbf{2}} \widehat{\boldsymbol{\theta}}_{2}
$$


where $\widehat{\boldsymbol{\theta}}_{2}=\left(\mathbf{G}_{\mathbf{2}}{ }^{T} \mathbf{G}_{\mathbf{2}}\right)^{-1} \mathbf{G}_{\mathbf{2}}{ }^{T} \mathbf{x}$ corresponds to the estimator of $\boldsymbol{\theta}_{2}$ under the assumption of a healthy electrical motor. Performing some computations leads to the following result

$$
\widehat{\boldsymbol{\theta}}_{2}=\left[\begin{array}{c}
\Re e(\widehat{c}) \\
\Im m(\widehat{c})
\end{array}\right]
$$

where $\widehat{c}$ is defined as

$$
\widehat{c}=\frac{2}{N^{2}-\left|q\left(\omega_{s}\right)\right|^{2}}\left(N X\left(\omega_{s}\right)-q^{*}\left(\omega_{s}\right) X^{*}\left(\omega_{s}\right)\right)
$$

where $(.)^{*}$ corresponds to the complex conjugate, and

$$
\begin{aligned}
q\left(\omega_{s}\right) & =\frac{\sin \left(N \omega_{s}\right)}{\sin \left(\omega_{s}\right)} e^{j \omega_{s}(N-1)} \\
X\left(\omega_{s}\right) & \triangleq \sum_{n=0}^{N-1} x[n] e^{-j \omega_{s} n}
\end{aligned}
$$

After some computations, it can be checked that the elements of $\mathbf{y}=[y[0], \cdots, y[N-1]]^{T}$ are given by

$$
y[n]=x[n]-|\widehat{c}| \cos \left(\omega_{s} n+\arg [\widehat{c}]\right)
$$

where $|\widehat{c}|$ and $\arg [\widehat{c}]$ correspond to the modulus and argument of $\widehat{c}$, which is the estimate of $c=a_{0} e^{j \phi_{0}}$.

Note that the complex scalar $X\left(\omega_{s}\right)$ simply corresponds to the Discrete-Time Fourier Transform (DTFT) of $x[n]$ evaluated at the normalized angular frequency $\omega_{s}$. Concerning the signal length, it should be mentioned that the particular values $N=$ $k \pi / \omega_{s}(k \in \mathbb{N})$ are attractive from a computational point of view. Indeed, for these particular values, the complex scalar $\widehat{c}$ reduces to $\widehat{c}=2 X\left(\omega_{s}\right) / N$

\section{B. Approximate Frequency Estimator}

The evaluation of the cost function in (12) requires the inversion of a $(L-2) \times(L-2)$ matrix. For $N \gg 1$, it can be shown that this cost function has a simple closed-form expression. Indeed, for $N \gg 1$, the matrix products $\mathbf{G}_{1}^{T}\left(\omega_{d}\right) \mathbf{G}_{1}\left(\omega_{d}\right)$ and $\mathbf{G}_{2}^{T} \mathbf{G}_{2}$ can be approximated by $(N / 2) \mathbf{I}_{L-2}$ and $(N / 2) \mathbf{I}_{2}$, respectively. It follows that $\mathbf{P}_{\mathbf{G}_{\mathbf{2}}} \approx \mathbf{I}_{N}$, and so the oblique projector can be simplified as $\mathbf{E}_{\mathbf{G}_{1} \mathbf{G}_{2}}\left(\omega_{d}\right) \approx(2 / N) \mathbf{G}_{1}\left(\omega_{d}\right) \mathbf{G}_{1}^{T}\left(\omega_{d}\right)$, which does not depend on $\mathbf{G}_{2}$. Consequently, the minimizing argument of (12) is asymptotically equal to

$$
\widehat{\omega}_{d}=\arg \max _{\omega_{d}} \sum_{\substack{k=-k_{1} \\ k \neq 0}}^{k_{2}} P_{y}\left(\omega_{s}+k \omega_{d}\right)
$$

where $P_{y}(\omega)$ is the periodogram of $y[n]$, which is defined as

$$
P_{y}(\omega) \triangleq \frac{1}{N}\left|\sum_{n=0}^{N-1} y[n] e^{-j \omega n}\right|^{2} .
$$

As compared to the exact cost function, the approximate one does not require any matrix inversion and explicitly depends on the periodogram of $y[n]$. Note that it is really important to use the periodogram of the interference-free signal $y[n]$ instead of the periodogram of the original signal $x[n]$. Indeed, the supply frequency, which has usually the largest amplitude, can introduce strong sidelobes in the periodogram of $x[n]$. These sidelobes critically affect the values of $P_{x}\left(\omega_{s}+k \omega_{d}\right)$ for $k \neq 0$. Using the interference-free signal instead of the original one allows to overcome this issue.

\section{Matched Subspace Fault Detector}

Let us consider the following hypothesis testing problem: the induction motor is healthy $\left(\mathcal{H}_{0}\right)$ or a fault is present $\left(\mathcal{H}_{1}\right)$. Mathematically, this hypothesis testing problem can be formulated as

$$
\begin{aligned}
& \mathcal{H}_{0}: \boldsymbol{\theta}_{1}=\mathbf{0}, \\
& \mathcal{H}_{1}: \boldsymbol{\theta}_{1} \neq \mathbf{0} .
\end{aligned}
$$

This problem can be solved by a Generalized Likelihood Ratio Test (GLRT). For the particular model in (6) with $\omega_{d}$ known, the GLRT reduces to a matched subspace detector [23], [36].

\section{A. Exact Fault Detector}

Let us consider the interference-free signal $\mathbf{y}$ computed by (18). When the noise variance is unknown, the matched subspace detector decides $\mathcal{H}_{1}$ if [23]

$$
\mathcal{T}(\mathbf{y})=\left(\frac{N-L}{L-2}\right) \frac{\mathbf{y}^{T} \mathbf{E}_{\mathbf{G}_{\mathbf{1}} \mathbf{G}_{\mathbf{2}}}\left(\omega_{d}\right) \mathbf{y}}{\mathbf{y}^{T}\left(\mathbf{I}_{N}-\mathbf{E}_{\left.\mathbf{G}_{\mathbf{1}} \mathbf{G}_{\mathbf{2}}\left(\omega_{d}\right)\right) \mathbf{y}}\right.}>\gamma
$$

where $\gamma$ is the test threshold. Note that when the fault-related (normalized) angular frequency $\omega_{d}$ is unknown, it can be replaced in (22) by its Maximum Likelihood estimator $\widehat{\omega}_{d}$ given in (12).

Regarding the detector performance, the probability of false alarm is given by

$$
\mathcal{P}_{F A}=\mathcal{Q}_{F_{L-2, N-L}}(\gamma),
$$

where $\mathcal{Q}_{F_{L-2, N-L}}($.$) is the complementary cumulative dis-$ tribution function of a $\mathrm{F}$ distribution with $L-2$ numerator degrees of freedom and $N-L$ denominator degrees of freedom. Furthermore, the probability of detection is given by

$$
\mathcal{P}_{D}=\mathcal{Q}_{F_{L-2, N-2}(\lambda)}(\gamma),
$$

where $\mathcal{Q}_{F_{L-2, N-L}(\lambda)}($.$) corresponds to the complementary$ cumulative distribution function of a non-central $\mathrm{F}$ distribution with $L-2$ numerator degrees of freedom, $N-L$ denominator degrees of freedom, and a noncentrality parameter $\lambda$ equal to

$$
\lambda=\frac{\boldsymbol{\theta}_{1}^{T} \mathbf{G}_{1}^{T}\left(\omega_{d}\right) \mathbf{P}_{\mathbf{G}_{\mathbf{2}}}^{\perp} \mathbf{G}_{1}\left(\omega_{d}\right) \boldsymbol{\theta}_{1}}{\sigma^{2}} .
$$

Note that the probability of detection $\mathcal{P}_{D}$ depends on several parameters such as the noise variance $\sigma^{2}$, the value of $\boldsymbol{\theta}_{1}$, the sample length $N$, and the detection threshold, $\gamma$.

In practice, the detection threshold $\gamma$ can be set according to a desired probability of false alarm, $\mathcal{P}_{F A}$, using (23). Since $\mathcal{P}_{F A}$ does not depend on $\sigma^{2}$, this test leads to a constant false alarm rate (CFAR) detector. 
TABLE I

SIGNAL PARAMETERS UNDER ASSUMPTION $\mathcal{H}_{1}(L=10)$.

\begin{tabular}{|c|ccccc|}
\hline Parameter & $k=-2$ & $k=-1$ & $k=0$ & $k=1$ & $k=2$ \\
\hline$a_{k}$ & 0.0004 & 0.018 & $\sqrt{2}$ & 0.0175 & 0.0003 \\
$\phi_{k}$ & 1.2 & 0.3 & 0.1 & 0.1 & 0.5 \\
\hline
\end{tabular}

\section{B. Approximate Fault Detector}

The implementation of the exact fault detector requires a matrix inversion. For $N \gg 1$, it can be shown that the statistical test $\mathcal{T}(\mathbf{y})$ has a simple closed-form that only depends on the periodogram of $y[n]$.

As provided in subsection III-B, the oblique projector $\mathbf{E}_{\mathbf{G}_{1} \mathbf{G}_{2}}\left(\omega_{d}\right)$ can be approximated by $(2 / N) \mathbf{G}_{1} \mathbf{G}_{1}^{T}$ when $N \gg 1$. It follows that the matched subspace detector reduces to

$$
\mathcal{T}_{a}(\mathbf{y})=\left(\frac{N-L}{L-2}\right) \frac{\sum_{\substack{k=-k_{1} \\ k \neq 0}}^{k_{2}} P_{y}\left(\omega_{s}+k \omega_{d}\right)}{\frac{1}{2}\|\mathbf{y}\|^{2}-\sum_{\substack{k=-k_{1} \\ k \neq 0}}^{k_{2}} P_{y}\left(\omega_{s}+k \omega_{d}\right)}>\gamma
$$

where $P_{y}(\omega)$ is defined in (20) and corresponds to the periodogram of $y[n]$ evaluated at $\omega$.

\section{Fault Detection Methodology}

The proposed induction machine fault detection methodology is based on four steps, which are summarized by Fig. 1. The proposed approach performance is tested on synthesized signals. Afterwards, its effectiveness is confirmed on experimental data for eccentricity fault, bearing faults, and broken rotor bars.

\section{Simulation RESULTS}

In this section, we evaluate the performance of the proposed techniques with synthetic signals. These signals are generated according to the signal model in (5) with the parameters provided in Table I. The (normalized) angular frequencies $\omega_{s}$ and $\omega_{d}$ are respectively set to $2 \pi \times 50 / F_{s} \mathrm{rad} /$ sample and $2 \pi \times 10.2 / F_{s} \mathrm{rad} / \mathrm{sample}$, with $F_{s}=2400 \mathrm{~Hz}$.

\section{A. Estimation of $\omega_{d}$}

In this subsection, we evaluate the performance of three estimators of $\omega_{d}$ : the exact estimator provided in (12), the approximate estimator provided in (19) and a simple technique without interference rejection, obtained by replacing $P_{y}(\omega)$ by $P_{x}(\omega)$ in (19). For these estimators, the optimization of the cost function is performed using the Nelder-Mead method with an initial value equal to $\omega_{d}=20 \pi / F_{s} \mathrm{rad} /$ samples. The estimation performance is evaluated in terms of Mean Square Error (MSE), which is estimated using $M=1000$ Monte Carlo trials as

$$
M S E_{\omega_{d}}=\frac{1}{M} \sum_{m=0}^{M-1}\left(\omega_{d}-\widehat{\omega}_{d}[m]\right)^{2} .
$$

where $\omega_{d}$ and $\widehat{\omega}_{d}[n]$ correspond to the true and estimated (normalized) fault-related angular frequencies, respectively. The
Stator current

samples $\mathbf{x}[n]$

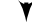

Compute the interference-free signal $\mathbf{y}[n]$ based on (18)

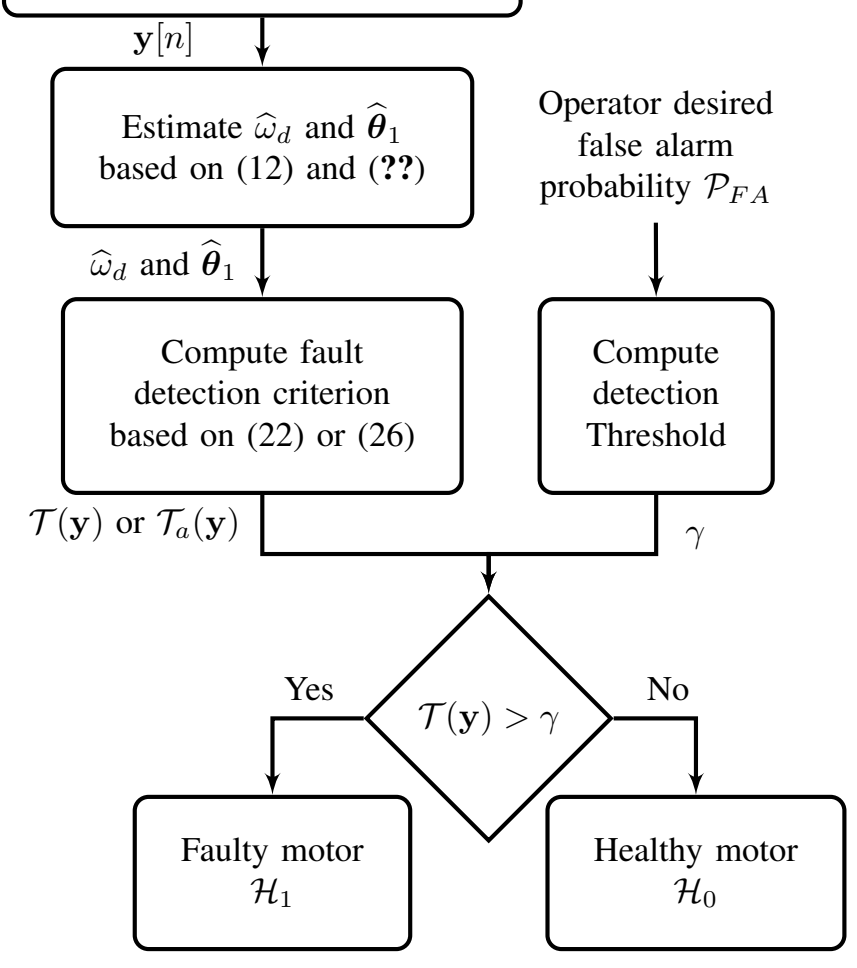

Fig. 1. Flowchart of the matched subspace detector.

MSE is also compared with exact and approximate CramérRao Bounds (CRBs). While the exact CRB must be evaluated numerically, it can be approximated for a large number of samples by

$$
\mathrm{CRB}_{a}\left(\omega_{d}\right)=\frac{24 \sigma^{2}}{N^{3} \sum_{k=-k_{1}}^{k 2} k^{2} a_{k}^{2}} .
$$

Note that the CRB for angular frequency decreases as the noise variance $\sigma^{2}$ increases and that the bound decreases as $1 / N^{3}$, making it quite sensitive to data record length $N$. This fact makes the frequency estimates more sensitive to data acquisition length $N$ than noise variance $\sigma^{2}$.

Figure 2 displays the MSE versus signal length, $N$, for a signal to noise ratio equal to $\mathrm{SNR}=30 \mathrm{~dB}$. We observe that the MSE of the exact estimator approaches the CRB when $N>300$ samples. Furthermore, this figure clearly shows the benefit of using the interference-free signal, $y[n]$. Indeed, the approximate estimator based on $y[n]$ clearly outperforms the approximate one without interference rejection. Furthermore, we note that the approximate estimator based on the interference-free signal, $y[n]$, periodically approaches the CRB. 


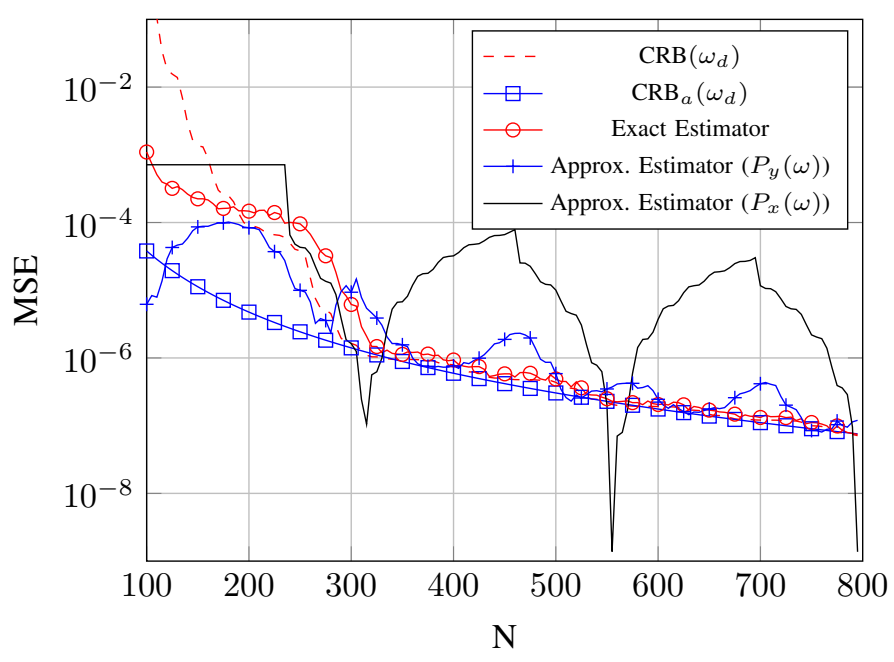

Fig. 2. Estimation of $\omega_{d}$ : Cramer-Rao Bounds (CRB) and MSE for frequency versus signal length $N(\mathrm{SNR}=30 \mathrm{~dB})$.

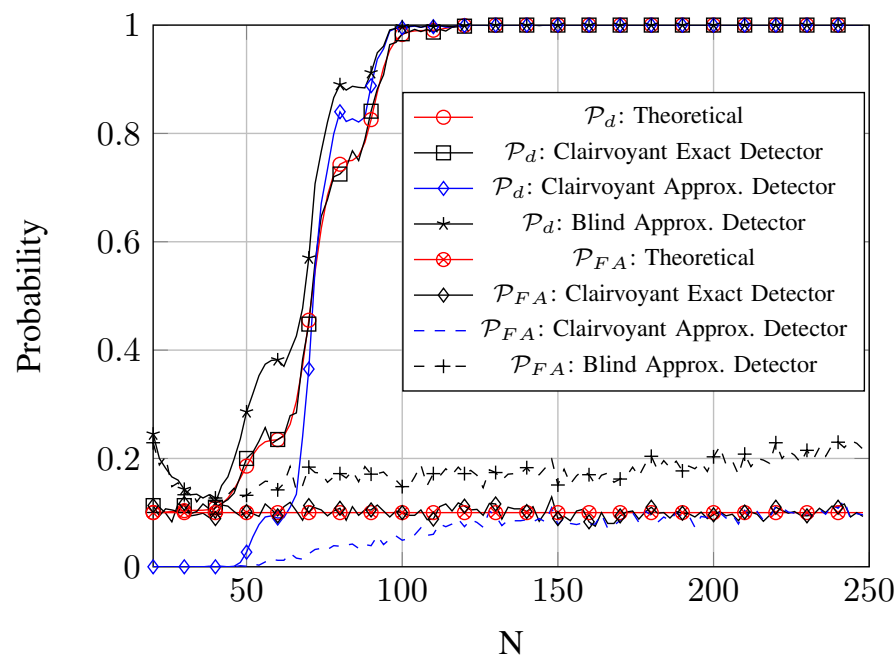

Fig. 3. Fault detection: Probability of detection, $\mathcal{P}_{d}$, and false alarm, $\mathcal{P}_{F A}$, versus signal length $N\left(\mathcal{P}_{F A}=0.1, \mathrm{SNR}=30 \mathrm{~dB}\right)$.

\section{B. Fault Detection}

In this subsection, the performance of the matched subspace detector is assessed on synthesized signals. Two detector types are considered in the following, which are the clairvoyant matched subspace detector that requires a perfect knowledge of $\boldsymbol{\theta}_{1}$ and $\omega_{d}$ and the blind matched subspace detector that replaces $\boldsymbol{\theta}_{1}$ and $\omega_{d}$ with their estimates $\widehat{\boldsymbol{\theta}}_{1}$ and $\widehat{\omega}_{d}$. The detection performance is usually assessed through two parameters, which are the probability of detection $P_{D}$ (i.e. the probability to detect $\mathcal{H}_{1}$ when $\mathcal{H}_{1}$ is true), and the probability of false alarm $P_{F a}$ (i.e. the probability to detect $\mathcal{H}_{1}$ when $\mathcal{H}_{0}$ is true).

Figure 3 presents the performance of three fault detectors for the discrimination between $\mathcal{H}_{0}$ and $\mathcal{H}_{1}$ with respect to $N$ $(\mathrm{SNR}=30 \mathrm{~dB})$. For $\mathcal{H}_{0}$, the signal parameters are obtained from Table I by setting $a_{k}=0$ for $k \neq 0$. The three considered fault detectors are the clairvoyant exact detector provided by (22), the clairvoyant approximate detector provided by (26), and the blind approximate detector given by (26) (obtained by replacing $\omega_{d}$ by its approximate estimator in (19)). For these three detectors, the threshold $\gamma$ is computed from the probability of false alarm, which is set to 0.1 . The detector performances are assessed through the Probability of Detection, $\mathcal{P}_{d}$, and Probability of False Alarm, $\mathcal{P}_{F A}$, which are estimated using $M=1000$ Monte Carlo trials. These probabilities are compared with the theoretical values of $\mathcal{P}_{F A}$ and $\mathcal{P}_{D}$ provided in section IV.

For the three detectors, we observe that the probability of detection, $\mathcal{P}_{D}$, becomes equal to 1 for $N \geq 100$ samples. Regarding $\mathcal{P}_{F A}$, we note that the probability of false alarm obtained with the approximate clairvoyant detector is close to the desired one for $N \geq 200$ samples. When the (normalized) fault-related angular frequency is unknown, Figure 3 also shows that the blind approximate detector seems to increase the false alarm rate since $\mathcal{P}_{F A} \geq 0.1$ when $N \geq 250$ samples.

\section{EXPERIMENTAL RESults}

This section illustrates the behavior of the exact and approximate blind detectors for eccentricity fault, bearing faults and broken rotor bars detection using experimental signals issued from different induction motors and for different load conditions.

\section{A. Experimental Setup Description}

Two mechanical faults and one electrical fault are considered in this section. These faults include eccentricity fault, rolling-element bearing faults, and broken rotor bars. The stator currents are measured using a data acquisition card and processed off-line on a standard desktop PC using Matlab ${ }^{\circledR}$.

1) Experimental setup for mechanical faults: Healthy machine and faulty ones with eccentricity fault and bearing faults have been tested. Each machine is a $230 / 400 \mathrm{~V}, 0.75 \mathrm{~kW}$, threephase induction machine with one pole pairs and $2780 \mathrm{rpm}$ rated speed. The machines under study are fed by a PWM inverter with a fundamental frequency that can be tuned from 0 to $60 \mathrm{~Hz}$. A DC generator is used to load the induction machines. The Experimental test bed is illustrated by Fig. 4 . The induction machines have two 6204-2 ZR type bearings (single row and deep groove ball bearings) with the following parameters: outside diameter is $47 \mathrm{~mm}$, inside diameter is 20 $\mathrm{mm}$, and pitch diameter $D$ is $31.85 \mathrm{~mm}$. Bearings have 8 balls with an approximate diameter $d$ of $12 \mathrm{~mm}$ and a contact angle of $0^{\circ}$. In the eccentricity-based faulty machine, eccentricity is introduced by acting on jack bolts on the circumference of each end-bell. Indeed, this will introduce a non-uniform air gap. Bearing faults are obtained by drilling holes of several diameters in the inner raceway (faults ranging from $0.178 \mathrm{~mm}$ in diameter to $1.016 \mathrm{~mm}$ ).

All the experiments were done in steady-state conditions. Induction machines stator currents have been measured using closed-loop (compensated) current transducers using Hall effect. These transducers are advantageous in terms of accuracy, linearity, low-temperature drift, wide frequency bandwidth, and high immunity to external interference. The stator currents acquisition is performed by a 24 bits LabJack UE9 acquisition card with $20 \mathrm{kHz}$ sampling frequency as illustrated by Fig. 5 . The bipolar analog-to-digital converter (ADC) of the LabJack 


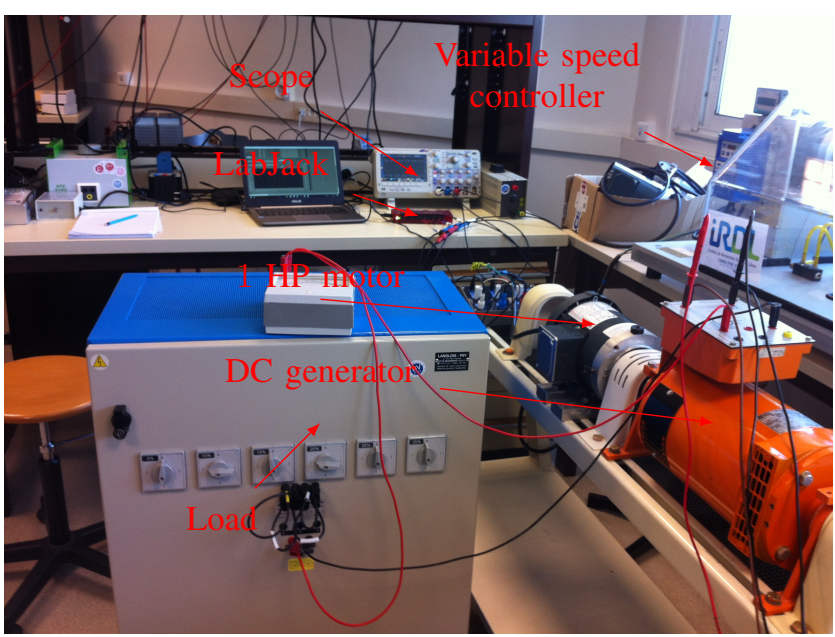

Fig. 4. Machinery fault simulator.

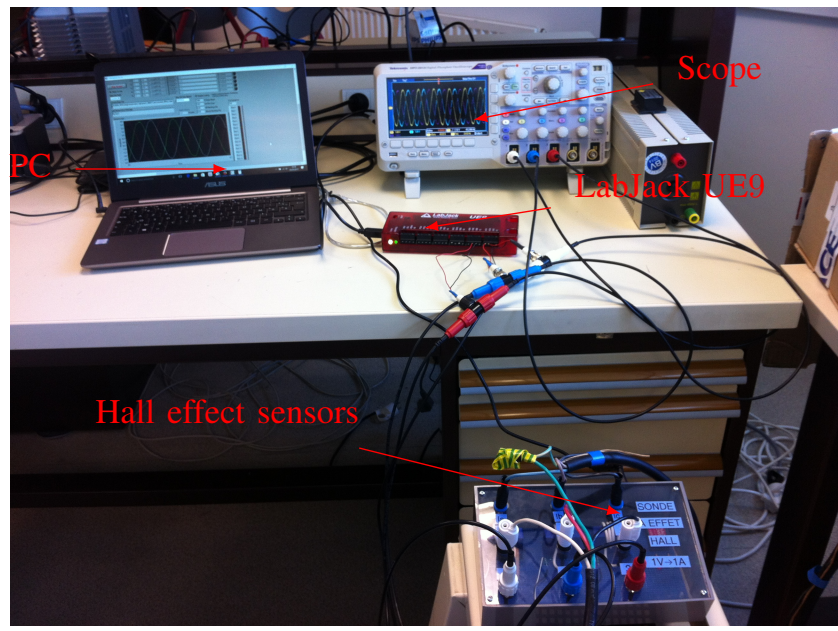

Fig. 5. Measurement devices.

UE9 has a range of -5 Volts to +5 Volts, which gives a voltage resolution of $0.59 \mu \mathrm{V} /$ bit.

2) Experimental setup for rotor electrical fault: The experimental bench consists of a three-phase $5 \mathrm{~kW}$ induction motor. The motor has $p=2$ pole pairs and a nominal toque $\Gamma=32$ N.m. The induction motor is supplied by a standard industrial inverter using a constant voltage to frequency ratio control strategy. The load is a DC motor with separate constant excitation connected to a resistor. The load level is controlled through an auto-transformer connected to the DC motor excitation. The motor fault has been simply achieved by drilling the rotor bar (broken bar emulation). Broken rotor bar significantly increases the currents flowing in the adjacent bars. These excessive currents increase the mechanical stresses on the adjacent bars and may consequently cause the breakage of the corresponding bars. Hence, one and two broken rotor bars have been considered for fault severity tracking.

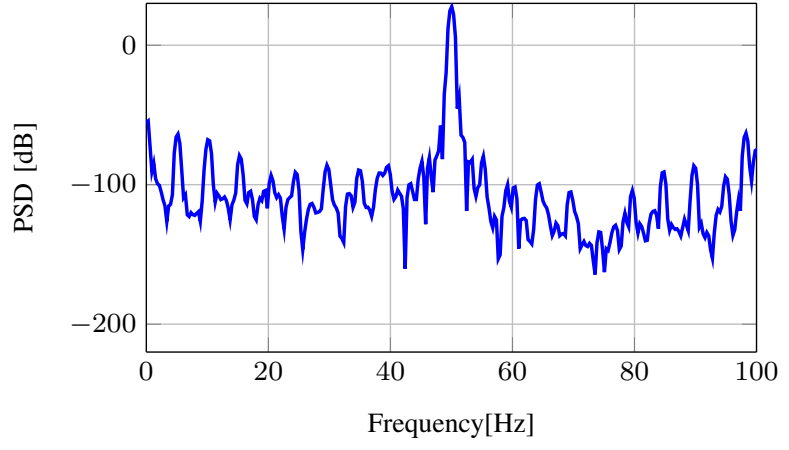

(a) PSD for healthy machine.

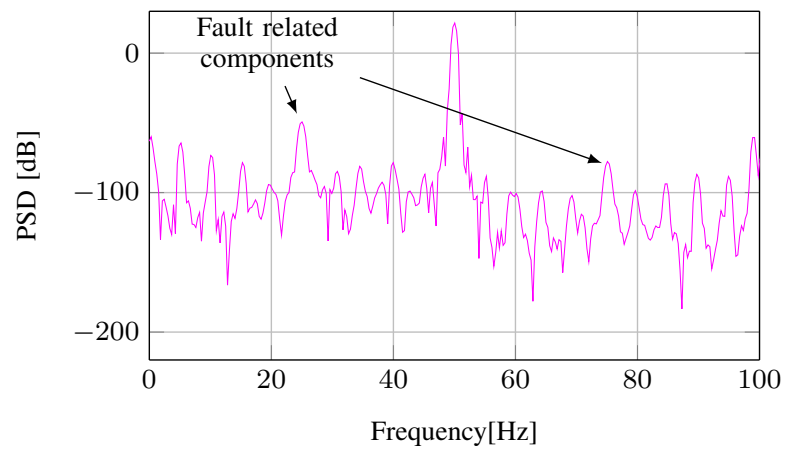

(b) PSD for eccentricity failure.

Fig. 6. Eccentricity fault: Healthy and faulty phase motor current data collected from the experimental setup ( $N=10000$, Hanning window).

\section{B. Eccentricity Fault Detection}

For illustration purposes, the stator current spectral signature of a motor with eccentricity fault is shown in Fig 6 . The current spectra shows an increase of the fault-related frequencies around the fundamental frequency. This behavior is identical for several load conditions. Consequently, it can be clearly recognized that a monitoring strategy based on these components can be efficiently used for detection purposes. Moreover, we observe that the noise component level is about $-110 \mathrm{~dB}$, which may eventually hide the low-amplitude fault frequency components for small data lengths. This noise component is due to the measurement chain, quantization errors and the induction machine operating conditions. Finally, we note that that the amplitude of the fundamental frequency is much more larger than those at the fault-related frequencies. When using a classical periodogram, the large amplitude of the fundamental component can mask the amplitude of the fault related components. To overcome this issue, the proposed technique explicitly removes the fundamental component from the raw signal using an oblique projection, and estimates the amplitude of the fault related components from the interference-free signal.

The original stator current signal has been low-pass filtered and down-sampled to $400 \mathrm{~Hz}$. Then, it has been processed using the proposed approach. The evolution of the fault detection criteria $\mathcal{T}(\mathbf{y})$ with respect to load conditions for several rotational speeds is given in Fig. 7. The detector threshold $\gamma$ obtained by setting $\mathcal{P}_{F A}=0.1$ is also shown for comparison. 


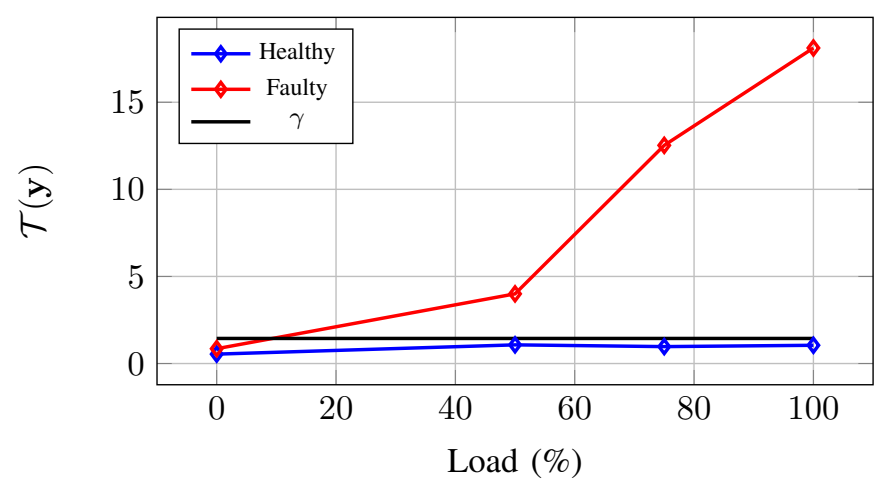

(a) Exact detector for $30 \mathrm{~Hz}$.

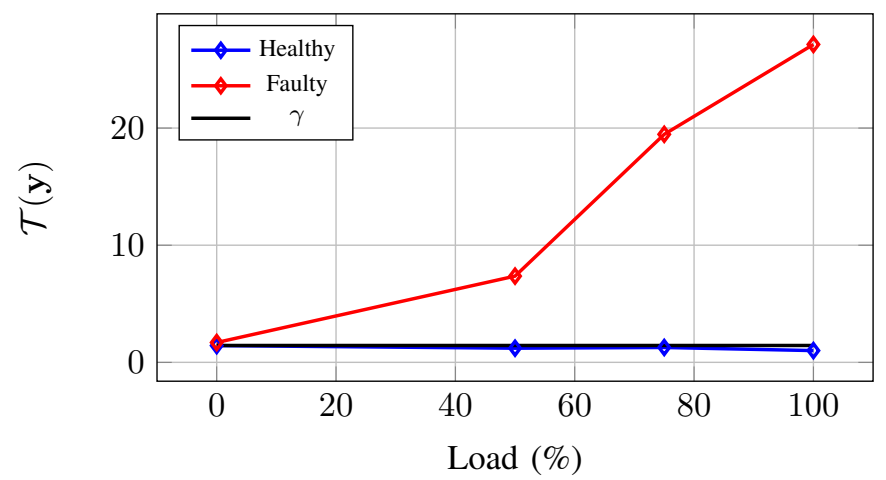

(b) Exact detector for $40 \mathrm{~Hz}$.

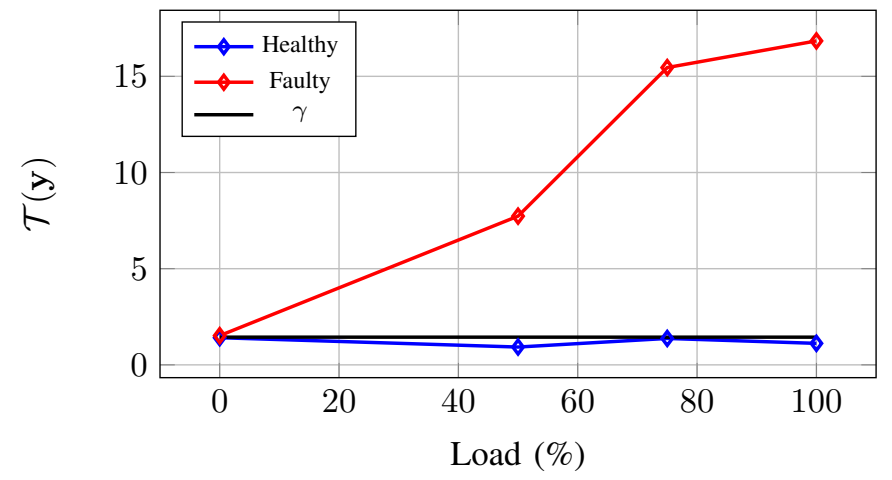

(c) Exact detector for $50 \mathrm{~Hz}$.

Fig. 7. Eccentricity fault: $\mathcal{T}(\mathbf{y})$ versus induction motor load for several rotational speeds.

For the healthy motor, we observe that the fault criteria $\mathcal{T}(\mathbf{y})$ is below the threshold $\gamma$ whatever the load and speed conditions are. For a motor with eccentricity fault, the detector allows to correctly detect the fault regardless of the rotational speed conditions. However, the fault may not be detected for an unloaded motor since it has a small influence on the stator current under small load. This is mainly due to the loading impact on the fault signature.

\section{Bearing Fault Detection}

The proposed fault detection criteria sensitivity has been evaluated according to bearing faults level. In fact, several fault severity degrees are considered in this study as summarized by table II.
TABLE II

BEARING FAULT DEGREE VERSUS INNER RACEWAY HOLE DIAMETER.

\begin{tabular}{|c||c|c|c|c|}
\hline $\begin{array}{c}\text { Fault } \\
\text { degree }\end{array}$ & 1 & 2 & 3 & 4 \\
\hline $\begin{array}{c}\text { Bearing hole } \\
\text { diameter (inches) }\end{array}$ & 0.007 & 0.014 & 0.02 & 0.03 \\
\hline
\end{tabular}

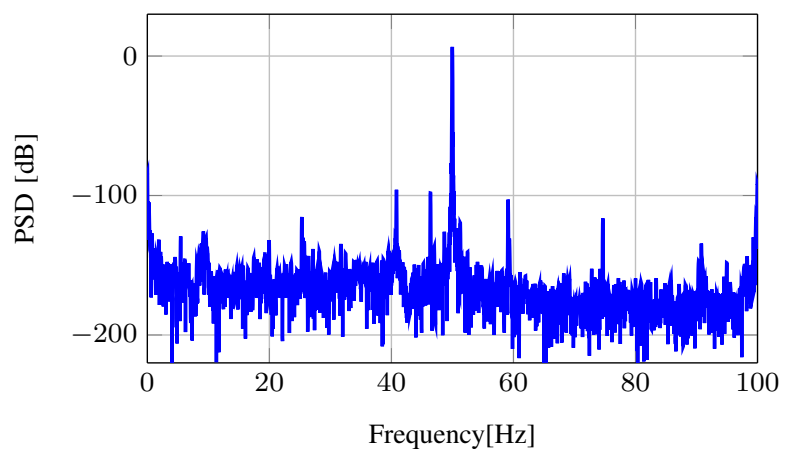

(a) PSD for healthy machine.

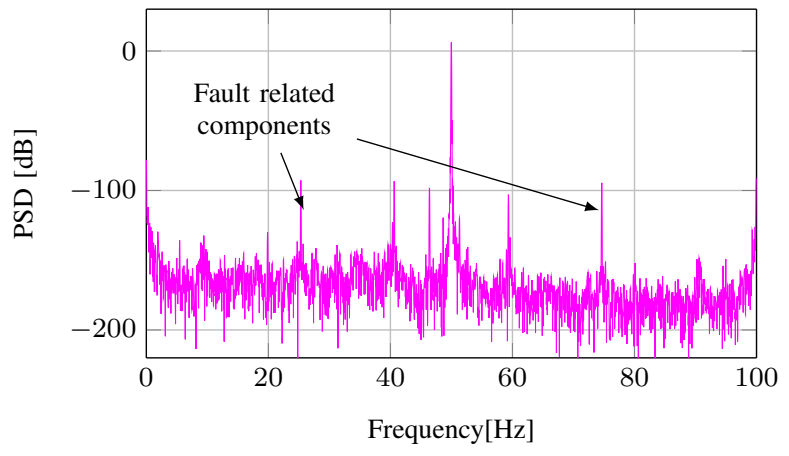

(b) PSD for bearing failure.

Fig. 8. Bearing fault: Healthy and faulty phase motor current data collected from the experimental setup ( $N=10000$, Hanning window).

The stator current PSD for healthy and faulty induction machines is given by Fig. 8. This figure shows clearly that bearing fault introduce some frequency components around the supply fundamental frequency. These components already exist on the stator current spectrum for healthy machine, which may be due to inherent eccentricity at the manufacturing stage, or harsh operating conditions. However, these components are extremely low for healthy machines and their amplitude increases when a fault is present. The results after the PSD computation using the periodogram for various fault conditions are given in table III. We observe that the noise level is about $-160 \mathrm{~dB}$. Furthermore, this table clearly shows that the fundamental frequency has higher amplitude than the fault related frequencies. Consequently, removing this component from the raw data can significantly enhance the detection of the fault related components estimates.

The raw data has been low-pass filtered and down-sampled to $400 \mathrm{~Hz}$. Then, it has been processed using the proposed approach. The evolution of the exact and approximate fault detection criteria $\mathcal{T}(\mathbf{y})$ and $\mathcal{T}_{a}(\mathbf{y})$ with respect to $N$ for several fault degrees is given by Fig. 9. The detector threshold $\gamma$ obtained by setting $\mathcal{P}_{F A}=0.1$, is also shown for comparison. For the healthy motor, we observe that the fault criteria $\mathcal{T}(\mathbf{y})$ 
TABLE III

AMPLITUDE OF THE BEARING FAULT RELATED COMPONENTS.

\begin{tabular}{|c|c|c|c|c|c|}
\hline \multirow{2}{*}{ Fault } & \multicolumn{2}{|c|}{ Fundamental } & \multicolumn{2}{c|}{ Fault related components } & Noise level \\
\cline { 2 - 5 } & $\begin{array}{c}\text { Frequency } \\
(\mathrm{Hz})\end{array}$ & $\begin{array}{c}\text { PSD } \\
(\mathrm{dB})\end{array}$ & $\begin{array}{c}\text { Frequency } \\
(\mathrm{Hz})\end{array}$ & $\begin{array}{c}\text { PSD } \\
(\mathrm{dB})\end{array}$ & \\
\hline Healthy & $f_{s}=50$ & 6.58 & $\begin{array}{c}f_{l}=25.33 \\
f_{u}=74.65\end{array}$ & $\begin{array}{c}-115.4 \\
-116.4\end{array}$ & -166.9 \\
\hline Sev.1 & $f_{s}=50$ & 6.17 & $\begin{array}{c}f_{l}=25.3 \\
f_{u}=74.68\end{array}$ & $\begin{array}{c}-99.1 \\
-106.7\end{array}$ & -162.3 \\
\hline Sev. 2 & $f_{s}=50$ & 6.35 & $\begin{array}{c}f_{l}=25.33 \\
f_{u}=74.65\end{array}$ & $\begin{array}{c}-92.72 \\
-94.57\end{array}$ & -167.6 \\
\hline Sev. 3 & $f_{s}=50$ & 6.33 & $\begin{array}{c}f_{l}=25.33 \\
f_{u}=74.65\end{array}$ & $\begin{array}{c}-86.23 \\
-87.69\end{array}$ & -160.4 \\
\hline Sev. 4 & $f_{s}=50$ & 6.42 & $\begin{array}{c}f_{l}=25.33 \\
f_{u}=74.65\end{array}$ & $\begin{array}{c}-83.16 \\
-84.89\end{array}$ & -161.3 \\
\hline
\end{tabular}

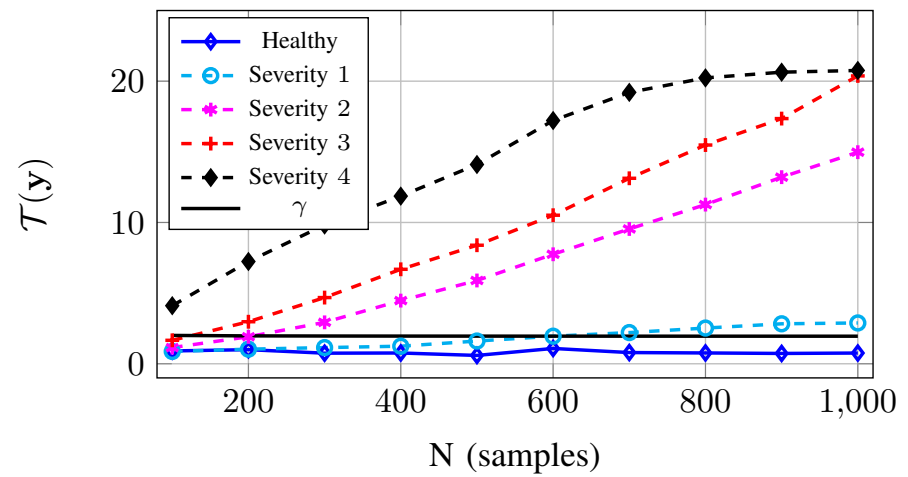

(a) Exact detector.

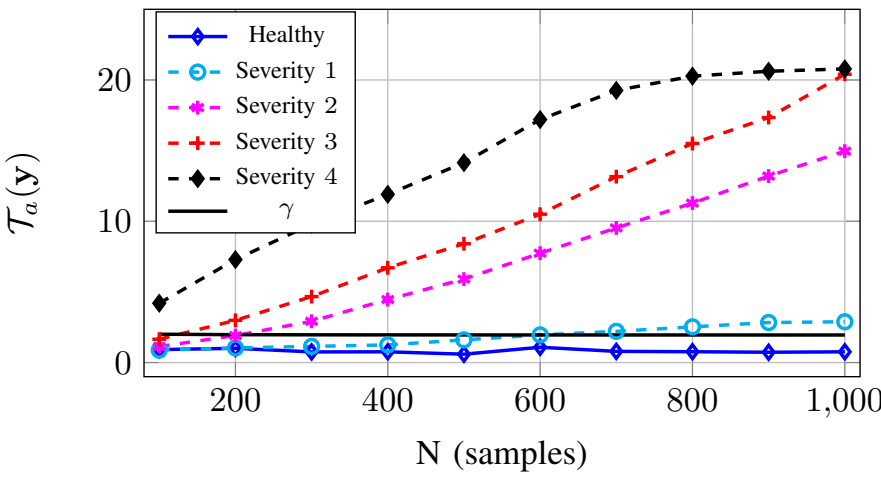

(b) Approximate detector.

Fig. 9. Bearing faults: $\mathcal{T}(\mathbf{y})$ and $\mathcal{T}_{a}(\mathbf{y})$ versus $N(L=6)$.

and $\mathcal{T}_{a}(\mathbf{y})$ are below the threshold $\gamma$ whatever the number of samples, $N$. For bearing fault, the detector requires at least $N=600$ samples to correctly detect the fault. For a severe bearing fault, we observe that a smaller number of samples is required. Moreover, the fault detection criteria increase as the fault degree increases.

\section{Broken Rotor Bars Fault Detection}

The healthy and the two faulty machines have been operated under steady state conditions with a fundamental frequency equal to $50 \mathrm{~Hz}$ at $50 \%$ load. The stator current has been acquired using a data acquisition board, with $F_{s}=20$ $\mathrm{kHz}$. The signal is further low-pass filtered, down-sampled to $400 \mathrm{~Hz}$.

The stator current power spectral density (PSD) for healthy and faulty induction machines is given by Fig. 10. This figure

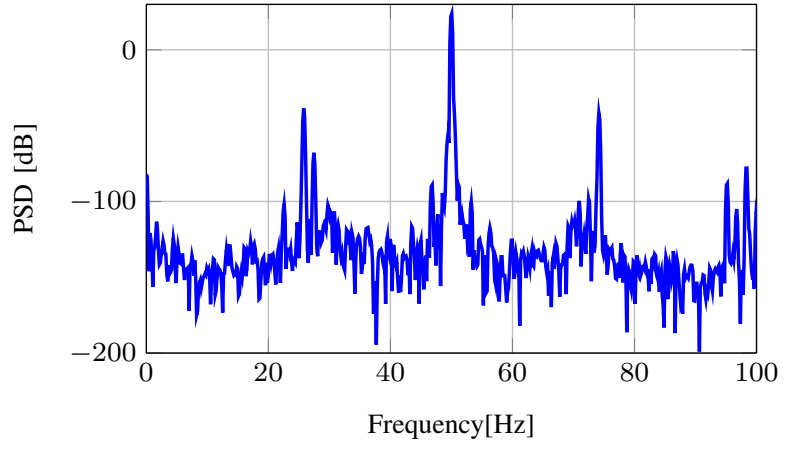

(a) PSD for healthy machine.

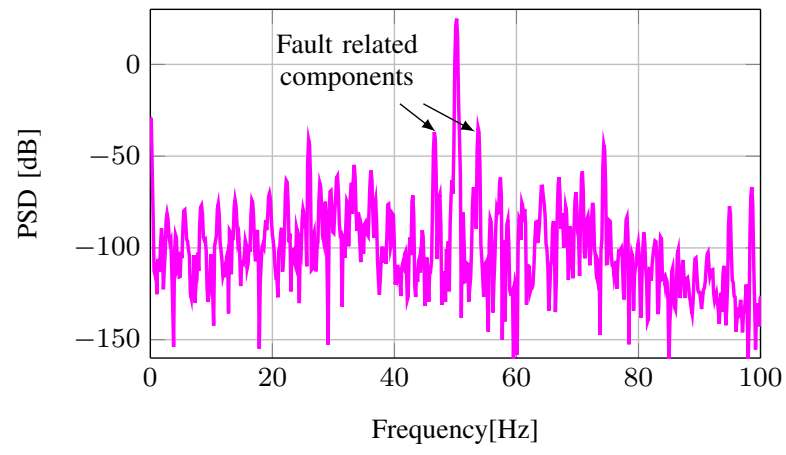

(b) PSD for 2 broken rotor bars.

Fig. 10. Broken rotor bars: Healthy and faulty phase motor current data collected from the experimental setup ( $N=20000$, Hanning window).

TABLE IV

AMPLITUDE OF THE BROKEN ROTOR BARS RELATED COMPONENTS.

\begin{tabular}{|c|c|c|c|c|c|}
\hline $\begin{array}{c}\text { Broken } \\
\text { bars }\end{array}$ & \multicolumn{2}{|c|}{ Fundamental } & \multicolumn{2}{c|}{ Fault related components } & \multirow{2}{*}{$\begin{array}{c}\text { Noise level } \\
(\mathrm{dB})\end{array}$} \\
\cline { 2 - 5 } & $\begin{array}{c}\text { Frequency } \\
(\mathrm{Hz})\end{array}$ & $\begin{array}{c}\text { PSD } \\
(\mathrm{dB})\end{array}$ & $\begin{array}{c}\text { Frequency } \\
(\mathrm{Hz})\end{array}$ & $\begin{array}{c}\text { PSD } \\
(\mathrm{dB})\end{array}$ & \\
\hline 0 & $f_{s}=50$ & 23.87 & $\begin{array}{c}f_{l}=46.84 \\
f_{u}=53.25\end{array}$ & $\begin{array}{c}-89.15 \\
-100.4\end{array}$ & -132.7 \\
\hline 1 & $f_{s}=50$ & 24.85 & $\begin{array}{c}f_{l}=47.3 \\
f_{u}=53.1\end{array}$ & $\begin{array}{c}-71.26 \\
-67.72\end{array}$ & -97.99 \\
\hline 2 & $f_{s}=50$ & 24.93 & $\begin{array}{c}f_{l}=46.54 \\
f_{u}=53.71\end{array}$ & $\begin{array}{l}-36.94 \\
-34.53\end{array}$ & -92.73 \\
\hline
\end{tabular}

clearly shows that broken rotor bars introduce several frequency components around the supply fundamental frequency. The fundamental frequency and the fault related frequency components for various fault degrees are summarized in table IV. In this table, only the upper $f_{u}$ and the lower $f_{l}$ sidebands are considered. It shows that the amplitude of the frequency components, signature of the fault, evolve according to the fault severity. Moreover, these frequencies are too close to the fundamental frequency which make it difficult to detect using the classical DTFT for short data measurement. Moreover, this table gives the noise level, which appears to be more important in the case of faulty machines. Visually, these differences can make the broken rotor bars more difficult to detect.

The evolution of the exact and approximate fault detection criteria $\mathcal{T}(\mathbf{y})$ and $\mathcal{T}_{a}(\mathbf{y})$ with respect to $N$ for several fault degrees is given by Fig. 11. The detector threshold $\gamma$ obtained by setting $\mathcal{P}_{f a}=0.1$ is also shown for comparison. For the healthy motor, we observe that the criteria $\mathcal{T}(\mathbf{y})$ and $\mathcal{T}_{a}(\mathbf{y})$ are below the threshold whatever the number of samples $N$. 


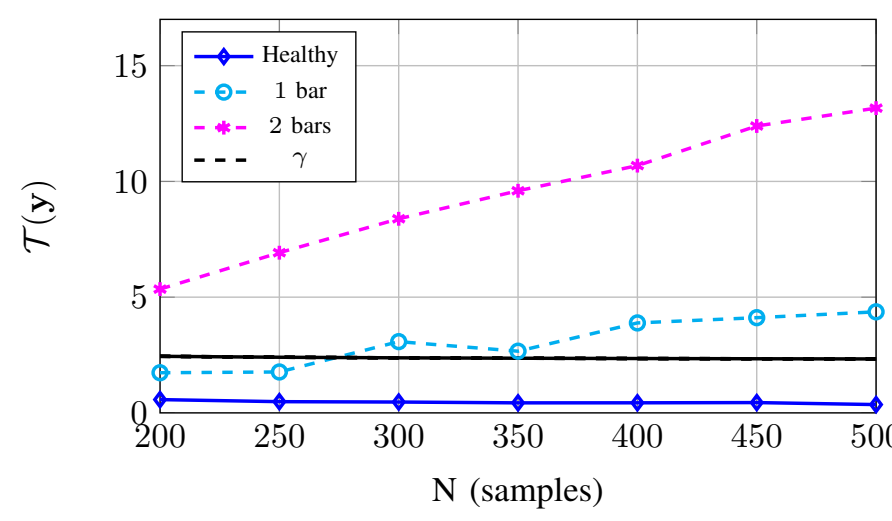

(a) Exact detector.

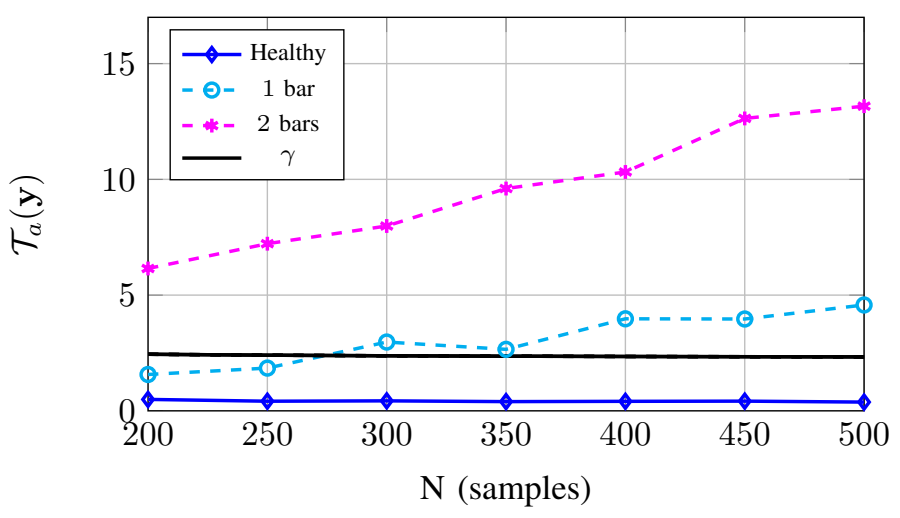

(b) Approximate detector.

Fig. 11. Broken rotor bars: $\mathcal{T}(\mathbf{y})$ and $\mathcal{T}_{a}(\mathbf{y})$ versus $N(L=18)$.

For one broken bar, the detector requires at least $N=400$ samples to correctly detect the fault. For two broken rotor bars, we observe that a smaller number of samples is required.

\section{CONCLUSION}

This paper has proposed a new faults detector for induction machines. The proposed detector is based on three steps, which are the estimation of the interference-free signal, the estimation of the fault-related angular frequency, and the application of a matched subspace detector. For the two last steps, we have derived exact and approximate algorithms. The approximate algorithm is simply based on the periodogram of the interference-free signal and does not require any matrix inversion, making it well suited for practical implementations. The effectiveness of the proposed approach has been verified for eccentricity fault, bearing faults, and broken rotor bars detection.

\section{REFERENCES}

[1] P. Tavner, L. Ran, and J. Penman, Condition monitoring of rotating electrical machines. IET, 2008, vol. 56.

[2] H. M. Hashemian and W. C. Bean, "State-of-the-art predictive maintenance techniques," IEEE Transactions on Instrumentation and measurement, vol. 60, no. 10, pp. 3480-3492, October 2011.

[3] P. Zhang, Y. Du, T. Habetler, and B. Lu, "A survey of condition monitoring and protection methods for medium-voltage induction motors," IEEE Transactions on Industry Applications, vol. 47, no. 1, pp. 34-46, Jan./Feb. 2011.
[4] J. de Jesus Rangel-Magdaleno, H. Peregrina-Barreto, J. M. RamirezCortes, P. Gomez-Gil, and R. Morales-Caporal, "FPGA-based broken bars detection on induction motors under different load using motor current signature analysis and mathematical morphology," IEEE Transactions on Instrumentation and Measurement, vol. 63, no. 5, pp. 10321040, May 2014.

[5] M. Blodt, J. Regnier, and J. Faucher, "Distinguishing load torque oscillations and eccentricity faults in induction motors using stator current Wigner distributions," IEEE Transactions on Industry Applications, vol. 45, no. 6, pp. 1991-2000, Nov./Dec. 2009.

[6] A. Bellini, F. Filippetti, C. Tassoni, and G. A. Capolino, "Advances in diagnostic techniques for induction machines," IEEE Transactions on Industrial Electronics, vol. 55, no. 12, pp. 4109-4126, December 2008.

[7] F. B. Batista, P. C. M. Lamim Filho, R. Pederiva, and V. A. D. Silva, "An empirical demodulation for electrical fault detection in induction motors," IEEE Transactions on Instrumentation and Measurement, vol. 65, no. 3, pp. 559-569, March 2016.

[8] N. Q. Hu, L. R. Xia, F. S. Gu, and G. J. Qin, "A novel transform demodulation algorithm for motor incipient fault detection," IEEE Transactions on Instrumentation and measurement, vol. 60, no. 2, pp. 480-487, Feb. 2011.

[9] M. B. K. Bouzid and G. Champenois, "New expressions of symmetrical components of the induction motor under stator faults," IEEE Transactions on Industrial Electronics, vol. 60, no. 9, pp. 4093-4102, December 2013.

[10] Y. Trachi, E. Elbouchikhi, V. Choqueuse, and M. E. H. Benbouzid, "Induction machines fault detection based on subspace spectral estimation," IEEE Transactions on Industrial Electronics, vol. 63, no. 9, September 2016.

[11] G. Bouleux, "Oblique projection pre-processing and TLS application for diagnosing rotor bar defects by improving power spectrum estimation," Mechanical Systems and Signal Processing, vol. 41, no. 1, pp. 301-312, 2013.

[12] A. Sadeghian, Z. Ye, and B. Wu, "Online detection of broken rotor bars in induction motors by wavelet packet decomposition and artificial neural networks," IEEE Transactions on Instrumentation and Measurement, vol. 58, no. 7, pp. 2253-2263, July 2009.

[13] A. Widodo and B.-S. Yang, "Support vector machine in machine condition monitoring and fault diagnosis," Mechanical Systems and Signal Processing, vol. 21, no. 6, pp. 2560-2574, 2007.

[14] P. V. J. Rodríguez and A. Arkkio, "Detection of stator winding fault in induction motor using fuzzy logic," Applied Soft Computing, vol. 8, no. 2, pp. 1112-1120, 2008.

[15] C. M. Bishop, "Pattern recognition," Machine Learning, vol. 128, 2006.

[16] J. Faiz, B. M. Ebrahimi, and H. A. Toliyat, "Effect of magnetic saturation on static and mixed eccentricity fault diagnosis in induction motor," IEEE Transactions on Magnetics, vol. 45, no. 8, pp. 3137-3144, Aug. 2009.

[17] T. Yang, H. Pen, Z. Wang, and C. S. Chang, "Feature knowledge based fault detection of induction motors through the analysis of stator current data," IEEE Transactions on Instrumentation and Measurement, vol. 65, no. 3, pp. 549-558, March 2016.

[18] A. Naha, A. K. Samanta, A. Routray, and A. K. Deb, "A method for detecting half-broken rotor bar in lightly loaded induction motors using current," IEEE Transactions on Instrumentation and Measurement, vol. 65 , no. 7, pp. 1614-1625, July 2016.

[19] A. Garcia-Perez, R. de Jesus Romero-Troncoso, E. Cabal-Yepez, and R. A. Osornio-Rios, "The application of high-resolution spectral analysis for identifying multiple combined faults in induction motors," IEEE Transactions on Industrial Electronics, vol. 58, no. 5, pp. 2002-2010, May 2011.

[20] Y.-H. Kim, Y.-W. Youn, D.-H. Hwang, J.-H. Sun, and D.-S. Kang, "High-resolution parameter estimation method to identify broken rotor bar faults in induction motors," IEEE Transactions on Industrial Electronics, vol. 60, no. 9, pp. 4103-4117, September 2013.

[21] E. Elbouchikhi, V. Choqueuse, and M. Benbouzid, "Induction machine faults detection using stator current parametric spectral estimation," Mechanical Systems and Signal Processing, vol. 52, pp. 447-464, 2015.

[22] Y. Trachi, E. Elbouchikhi, V. Choqueuse, M. Benbouzid, and T. Wang, "A novel induction machine faults detector based on hypothesis testing," IEEE Transactions on Industry Applications, vol. 53, no. 3, pp. 30393048, May-June 2017.

[23] L. L. Scharf and B. Friedlander, "Matched subspace detectors," IEEE Trans. Signal Process., vol. 42, no. 8, pp. 2146-2157, 1994.

[24] G. Joksimovic, M. Durovic, J. Penman, and N. Arthur, "Dynamic simulation of dynamic eccentricity in induction machines-winding function 
approach," IEEE Trans. Energy Conversion, vol. 15, no. 2, pp. 143-148, June 2000.

[25] J. Faiz, B. M. Ebrahimi, B. Akin, , and H. A. Toliyat, "Finite-element transient analysis of induction motors under mixed eccentricity fault," IEEE Trans. Magn., vol. 44, no. 1, pp. 66-74, Jan. 2008.

[26] F. Immovilli, C. Bianchini, M. Cocconcelli, A. Bellini, and R. Rubini, "Bearing fault model for induction motor with externally induced vibration," IEEE Transactions on Industrial Electronics, vol. 60, no. 8 , pp. 3408-3418, August 2013.

[27] M. Blodt, P. Granjon, B. Raison, and G. Rostaing, "Models for bearing damage detection in induction motors using stator current monitoring," IEEE Transactions on Industrial Electronics, vol. 55, no. 4, pp. 18131822, April 2008.

[28] P. Shi, Z. Chen, Y. Vagapov, and Z. Zouaoui, "A new diagnosis of broken rotor bar fault extent in three phase squirrel cage induction motor,' Mechanical Systems and Signal Processing, vol. 42, no. 1, pp. 388403, January 2014.

[29] F. Gu, T. Wang, A. Alwodai, X. Tian, Y. Shao, and A. Ball, "A new method of accurate broken rotor bar diagnosis based on modulation signal bispectrum analysis of motor current signals," Mechanical Systems and Signal Processing, vol. 50, pp. 400-413, January 2015.

[30] L. Saidi, F. Fnaiech, H. Henao, G. Capolino, and G. Cirrincione,
"Diagnosis of broken-bars fault in induction machines using higher order spectral analysis," ISA transactions, vol. 52, no. 1, pp. 140-148, January 2013.

[31] M. Rosenblatt, "A central limit theorem and a strong mixing condition," Proceedings of the National Academy of Sciences, vol. 42, no. 1, pp. 43-47, 1956.

[32] P. Stoica and P. Babu, "The gaussian data assumption leads to the largest cramér-rao bound [lecture notes]," IEEE Signal Processing Magazine, vol. 28, no. 3, pp. 132-133, May 2011.

[33] P. Stoica and Y. Selen, "Model-order selection: a review of information criterion rules," IEEE Signal Processing Magazine, vol. 21, no. 4, pp. 36-47, July 2004

[34] S. Kay, Fundamentals of Statistical Signal Processing: Estimation Theory. Prentice-Hall signal processing series, 1993, 17th Printing.

[35] G. H. Golub and V. Pereyra, "The differentiation of pseudo-inverses and nonlinear least squares problems whose variables separate," SIAM Journal on numerical analysis, vol. 10, no. 2, pp. 413-432, 1973.

[36] R. T. Behrens and L. L. Scharf, "Signal processing applications of oblique projection operators," IEEE Transactions on Signal Processing, vol. 42, no. 6, pp. 1413-1424, June 1994 